\title{
Time-Varying Risk Attitude and Conditional Skewness
}

\author{
Zhifeng Liu, ${ }^{1}$ Tingting Zhang, ${ }^{1}$ and Fenghua Wen ${ }^{2}$ \\ ${ }^{1}$ College of Management and Economics, Tianjin University, Tianjin 300072, China \\ ${ }^{2}$ Business School, Central South University, Changsha 410012, China
}

Correspondence should be addressed to Fenghua Wen; wfh@amss.ac.cn

Received 28 January 2014; Accepted 16 May 2014; Published 4 June 2014

Academic Editor: Chuangxia Huang

Copyright (C) 2014 Zhifeng Liu et al. This is an open access article distributed under the Creative Commons Attribution License, which permits unrestricted use, distribution, and reproduction in any medium, provided the original work is properly cited.

\begin{abstract}
Much literature finds that the skewness in the return distribution is negatively correlated with the risk premium coefficient, and speculation is the reason for the skewness in the return distribution. As further research, this paper, first taking up the time-varying property of the risk premium coefficient, proposes a GARCH-M model with a time-varying coefficient of the risk premium for an empirical study of the correlation between the conditional skewness in the return distribution and the time-varying risk attitude. The empirical study indicates that the coefficient of the risk premium varies with the time, and even in a mature market the conditional skewness in the return distribution is negatively correlated with the time-varying coefficient of the risk premium.
\end{abstract}

\section{Introduction}

The study of the skewness in the return distribution has gradually become the hot topic in Finance. Much literature ([1-3], etc.) finds that there exists more or less skewness in the return distribution.

The negatively skewed return distribution will increase the loss probability, while the positively skewed one will increase the possibility of gaining. Building an optimal asset portfolio allowing for the skewness has been one of the most attractive topics in investment portfolio research. For example, Samuelson [4], Lai [5], Prakash et al. [6], Canela and Collazo [7], and Zakamouline and Koekebakker [8] are all related to this field. Meanwhile, after recognizing the importance of the skewness, it has been given the same importance as the mean and the variance in researching in the problem of security pricing (see, e.g., [9-12]).

More and more scholars have begun to study the properties of the skewness due to the fact that it plays an important role in asset pricing. How the skewness changes with the time under the influence of various factors is one of the most densely studied topics. In specifying most of the models in the past, the distribution assumption did not involve the time variation of the skewness. For example, it was assumed, to the effect, that the skewness does not vary with the time in the GARCH model proposed in Bollerslev [13]. Some scholars discussed the persistence of the skewness, but their conclusions are not consistent. Singleton and Wingender [14] find that the positive skew is very likely to be negative in the next time period, while the negative skew will very probably turn to be positive in the next period of time; Lau and Wingender [15] believe that the skewness approaches to nothing in the long run, and some researchers hold that there does not exist persistence in the skewness (see, e.g., $[16,17])$.

A number of studies have argued for the existence of the time variation of the skewness from various perspectives, among which Harvey and Siddique [18] study is a pioneering study of great significance on the time variation of the skewness. On the basis of a GARCH model, they studied the time variation of the skewness and proposed an autoregressive conditional skewness model with the empirical results showing that the skewness in the return distribution varies with the time. Following their thinking, most of later research studied the time-variation problem in the framework of the GARCH-type models [19]. Higher moments models have difficulties in parameter estimation due to the number of parameters. León et al. [20] estimated the autoregressive conditional variance, the skewness, and the kurtosis using the Gram-Charlier series expansion of the normal density function, as this estimation procedure can incorporate the skewness and the kurtosis in the model as parameters and thus solved the problem of parameter estimation in higher 
moments models. Chan [21] modeled the time variation of higher moments using maximum entropy density (MED) and produced relatively better results.

Due to the fact that the reasons for the skewness in the return have not been understood, consensus cannot be achieved on the constraints for the optimization and the pricing kernel process in portfolio selection, although advances have been made in the research and the empirical studies of skewness. Consequently, more and more researchers have switched their research foci to the reasons for the skewness.

Bakshi et al. [22] believed that investors risk aversion will lead to the negative skewness in the return distribution. Ekholm and Pasternack [23] built a theoretic model on the basis of the negative news threshold hypothesis, and with empirical evidence they believe that the different releasing policies for positive and negative information are responsible for the skewness in the return distribution. Wen et al. [24] suggested that, with investors' overconfidence and regret aversion, their reaction to the nonlinear arrival of information will lead to the skewness in the return distribution, which was supported by their simulation. Bae et al. [25] find that the low level of corporate governance may be the cause of the positive skewness in the return distribution. $\mathrm{Xu}$ [26] finds that the skewness in the return distribution is positively correlated with the return of the current period but negatively correlated with that of the last period, which indicates that the skewness in the return distribution may be related to investors' reactions to the return. Besides, many scholars have attempted to identify the reasons for the skewness from different perspectives, such as trading volume, and the heterogeneity of the investors [27, 28], but an agreement has yet to be achieved on the conclusion of the reasons.

Wen and Yang [29] suggested that skewness is related to investors' risk attitude in stock market and too much speculative behavior in the market is responsible for the positive skewness in the return distribution. They employed a GARCH-M model to test the composite indices of 33 securities markets, and the empirical evidences showed that the skewness in the return distribution is significantly negatively correlated with the risk premium coefficient. This conclusion was derived from the comparison of different markets, but many factors, such as the differences of the cultural background of market players, and the microstructure of the markets may influence the relationship between the speculation in the market and the skewness in the return distribution, so it is necessary to further study the correlation between them on the dimension of time.

Based on Wen and Yang [29], the autoregressive conditional skewness model in Harvey and Siddique [18] can be introduced to characterize the conditional skewness process in order to further examine the correlation between the skewness in the return distribution and the risk premium coefficient on the dimension of time. GARCH-M can be employed to examine the tradeoff between the risk and the risk premium in investors' investment decision, but in the GARCH-M model, the risk premium coefficient is held constant in a certain period of time and thus cannot generate the time-varying risk premium series corresponding to the conditional skewness process. Anderson et al. [30] proposed an
ANST-GARCH (Asymmetric Nonlinear Smooth-Transition GARCH) model by introducing a smooth-transition specification to extend the GARCH model and studied the time variation of the risk premium using the ANST-GARCH-M model. In Anderson's model, the time variation of the risk premium is essentially related to the error of the last period (the unexpected return), and the reason for the time variation has not been thoroughly discussed.

This paper suggests that the time variation of the risk premium coefficient is related not only to the unexpected return but also to the risk and the speculation of the prior periods. Therefore, we first construct a time-varying risk premium coefficient incorporated GARCH-M model to study the time variation of the risk premium coefficient. On the basis of the above model, we propose a time-varying risk premium coefficient incorporated GARCH-M model with Harvey and Siddique's [18] autoregressive conditional skewness model to introduce the conditional skewness process. Finally, we select 14 most representative stock composite indices as samples to conduct an empirical investigation.

\section{The Relationship between Risk Attitude and Skewness}

2.1. Measure for Risk Attitude: Risk Premium Coefficient. Wen and Yang [29] argued that, "the biggest difference between investors and speculators is their attitude towards risk, most investors are risk averse, while most speculators are risk tolerant," and "the more speculative a market is, the smaller average coefficient of risk premium $\gamma$ is." Then they used the $\gamma$ coefficient in the GARCH-M model as the measure for risk attitude. The $\gamma$ coefficient in the GARCH-M model describes the average risk premium investors demand for a unit risk in the market, that is, risk attitude or risk tolerance, also called the risk premium coefficient. The expression of the GARCHM model is

$$
\begin{aligned}
& r_{t}=c+x_{t} \beta+\gamma \sqrt{h_{t}}+\varepsilon_{t}, \\
& \varepsilon_{t}=\sqrt{h_{t}} \cdot v_{t}, \\
& h_{t}=\alpha_{0}+\sum_{i=1}^{q} \alpha_{i} \varepsilon_{t-i}^{2}+\sum_{j=1}^{p} \theta_{j} h_{t-j},
\end{aligned}
$$

where $v_{t}$ is i.i.d, $E\left(v_{t}\right)=0, D\left(v_{t}\right)=1$, and $\sum_{i=1}^{q} \alpha_{i}+\sum_{j=1}^{p} \theta_{j}<$ 1.

In this model, the return rate is divided into three parts: the average return rate $c+x_{t} \beta$ related to exogenous variables, the risk premium $\gamma \sqrt{h_{t}}$, and the volatility return rate related to exogenous shocks (it is regarded as the gain not expected by investors, i.e., the unexpected gain). Obviously,

$$
\gamma=\frac{\Delta r_{t}}{\Delta \sqrt{h_{t}}}
$$

which shows that $\gamma$ is the risk premium coefficient for a unit of risk. So the risk premium coefficient $\gamma$ can be used to measure the magnitude of the compensation for the risk investors take 
TABLE 1: Basic statistics of the daily return series of indices.

\begin{tabular}{|c|c|c|c|c|c|c|}
\hline & Mean & Std. dev. & Skewness & Jarque-Bera & ADF test & ARCH-LM test \\
\hline S\&P 500 & -0.006210 & 1.400254 & -0.114384 & 6587.713 & -38.3026 & 153.6778 \\
\hline Dow Jones & -0.000915 & 1.317075 & 0.047682 & 6299.268 & -37.8115 & 150.5500 \\
\hline NASDAQ & -0.000440 & 1.747697 & 0.175155 & 2298.068 & -37.5163 & 100.7235 \\
\hline NYSE & 0.002528 & 1.397271 & -0.283905 & 9121.484 & -37.44753 & 190.2067 \\
\hline Nikkei225 & -0.011831 & 1.660565 & -0.292542 & 3821.667 & -48.86196 & 325.9931 \\
\hline FTSE 100 & -0.005793 & 1.357928 & -0.106906 & 3927.123 & -21.9967 & 153.3013 \\
\hline SSE & 0.019730 & 1.714406 & -0.105263 & 1629.944 & -27.6192 & 5.505159 \\
\hline DAX & -0.002373 & 1.692539 & 0.070301 & 1798.858 & -49.73979 & 119.7851 \\
\hline CAC 40 & -0.016852 & 1.587710 & 0.052661 & 2746.579 & -23.62872 & 111.7417 \\
\hline GSPTSE & 0.012879 & 1.250443 & -0.679786 & 9174.220 & -51.28554 & 161.5086 \\
\hline MIBTEL & -0.030404 & 1.316993 & -0.158677 & 4999.875 & -20.68796 & 123.2172 \\
\hline IGBM & 0.020879 & 1.364191 & -0.061860 & 4384.783 & -46.61378 & 123.3914 \\
\hline BVSP & 0.067122 & 2.025965 & -0.093354 & 1355.060 & -46.66775 & 131.7443 \\
\hline Hangseng & 0.017219 & 1.676433 & 0.037793 & 7002.364 & -48.77268 & 223.4757 \\
\hline
\end{tabular}

Note: the J-B statistic, the ADF test, and the ARCH-LM test are all at $1 \%$ significance level.

in the market. Compared to an investor, a speculator's risk tolerance is higher, that is to say, the risk premium coefficient is lower $\gamma$. The more speculation there is in a market, the smaller the average risk premium coefficient $\gamma$ is.

2.2. Robust Measure for Skewness. For a return series $\left\{R_{t}\right\}$, the most widely used measure for the skewness is

$$
\mathrm{SK}_{1}=E\left(\frac{R_{t}-\mu}{\delta}\right)^{3}
$$

where $\mu=E\left(R_{t}\right), \delta^{2}=E\left(R_{t}-\mu\right)^{2}$. But much literature (e.g., [31]) finds that $\mathrm{SK}_{1}$ is very sensitive to outliers and thus not a robust measure. This paper adopted the robust skewness measure proposed by Groeneveld and Meeden [32]:

$$
\begin{aligned}
\mathrm{SK}_{2} & =\frac{\int_{0}^{0.5}\left\{F^{-1}(1-\alpha)+F^{-1}(\alpha)-2 Q_{2}\right\} d \alpha}{\int_{0}^{0.5}\left\{F^{-1}(1-\alpha)-F^{-1}(\alpha)\right\} d \alpha} \\
& =\frac{\mu-Q_{2}}{E\left|R_{t}-Q_{2}\right|} .
\end{aligned}
$$

2.3. Samples and Statistics. According to the World Bank Report 2009, the GDP of the top 10 countries accounted for $65.4 \%$ of the world GDP. The 10 countries were USA, Japan, China, Germany, France, UK, Italy, Brazil, Russia, and Spain. This paper would have chosen their representative stock indices from the Yahoo finance as the samples, and the time duration is January 1, 2001, to December 31, 2009. As there are no stock index data of Russia in Yahoo finance, this paper chose Canada which was the eleventh in 2008 world GDP ranking as the substitute for data source consistence. These representative indices are S\&P 500, Dow Jones, Nasdaq, NYSE, Japan's Nikkei 225, China's SSE and China Hongkong's Hangseng, Germany's DAX, France's CAC 40, UK's FTSE 100, Italy's MIBTEL, Brazil's BVSP, Spain's IGBM, and Canada's GSPTSE, 14 indices all together, which include most of the

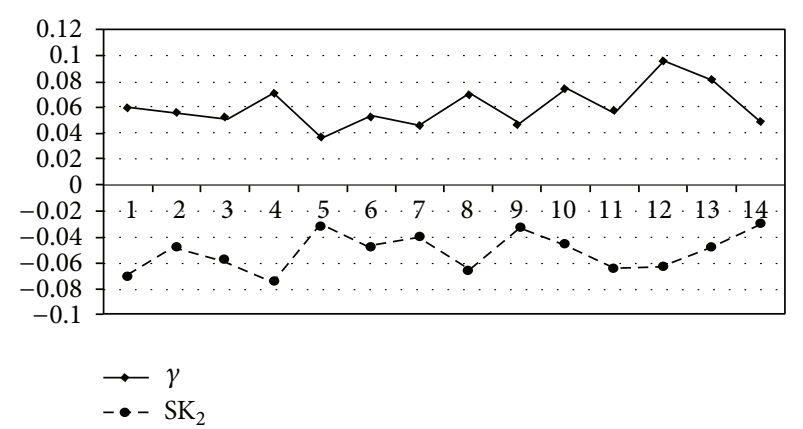

FIGURE 1: Relationship between coefficient $\gamma$ and $\mathrm{SK}_{2}$ measurement.

representative stock markets in North America, Europe, and Asia. The return is calculated with $r_{t}=100 *\left(\ln P_{t}-\ln P_{t-1}\right)$. The basic statistics of the daily return of the above chosen indices are shown in Table 1.

The J-B statistics in Table 1 show that all the return series of the above indices are not normal, but more or less rightor left-skewed (skewness $\neq 0$ ). The ADF test for the return series shows that all the series are stationary. The results of the ARCH-LM test indicate that the accompanying probabilities are all less than those at the $1 \%$ significance level, which implies that there exists error ARCH effect in the error series. Therefore we employ the GARCH type model to capture the volatilities of the indices.

2.4. Empirical Results. Following the thinking of Wen and Yang [29], this paper first compared cross-sectionally the correlation between the risk premium coefficient and the skewness of the 14 stock indices. The results are tabulated in Table 2 and Figure 1. We can see that as the usual skewness measure is very sensitive to the outliers, the values of $\mathrm{SK}_{1}$ for various indices are quite different from each other, while the values of the robust measure $\mathrm{SK}_{2}$ are obviously rather consistent with each other. Further statistical analysis found that the 
TABLE 2: Risk premium coefficients and skewness of indices.

\begin{tabular}{|c|c|c|c|c|}
\hline & $\mathrm{SK}_{1}$ & $\mathrm{SK}_{2}$ & $\gamma$ & $P$ value \\
\hline S\&P 500 & -0.114384 & -0.070551 & 0.059168 & 0.0026 \\
\hline Dow Jones & 0.047682 & -0.047682 & 0.055383 & 0.0046 \\
\hline NASDAQ & 0.175155 & -0.057890 & 0.050780 & 0.0108 \\
\hline NYSE & -0.283905 & -0.074509 & 0.070776 & 0.0004 \\
\hline Nikkei225 & -0.292542 & -0.031569 & 0.036404 & 0.0763 \\
\hline FTSE 100 & -0.106906 & -0.048346 & 0.052449 & 0.0098 \\
\hline SSE & -0.105263 & -0.040100 & 0.046433 & 0.0096 \\
\hline DAX & 0.070301 & -0.066459 & 0.068993 & 0.0005 \\
\hline CAC 40 & 0.052661 & -0.032634 & 0.047085 & 0.0193 \\
\hline GSPTSE & -0.679786 & -0.045354 & 0.074935 & 0.0001 \\
\hline MIBTEL & -0.158677 & -0.065010 & 0.056490 & 0.0044 \\
\hline IGBM & -0.061860 & -0.063446 & 0.095071 & 0.0000 \\
\hline BVSP & -0.093354 & -0.048321 & 0.080769 & 0.0001 \\
\hline Hangseng & 0.037793 & -0.029994 & 0.048903 & 0.0111 \\
\hline
\end{tabular}

correlation between the risk premium coefficient and $\mathrm{SK}_{1}$ for the 14 stock indices is -0.21613 , while the correlation between the robust skewness measure $\mathrm{SK}_{2}$ and the risk premium coefficient is -0.54081 , both being significantly smaller than zero, which shows the skewness in the return distribution and the risk premium coefficient are significantly negatively associated. The above empirical results are consistent with the conclusion in Wen and Yang [29], which has further proved that the skewness in the return distribution is closely related to the degree of speculation in the market.

\section{Time-Varying Risk Premium Coefficient and Skewness}

The above negative correlation between the skewness in the return distribution and the risk premium coefficient was derived from the returns of different markets at the same time period. In the foregoing section, we have pointed out that many factors like different cultural background and different microstructure of different markets may influence the relationship between the degree of speculation and the skewness in the return distribution. If the research is confined in the same market, these factors can be ignored. Therefore it is necessary to further study the correlation between the skewness in the return distribution and the risk premium coefficient in the same market on the dimension of time.

3.1. Time Variation of Risk Premium Coefficient. In fact, the GARCH-M model has an implied assumption that the return compensation investors demand for a unit of risk is invariant in a certain period of time. Wen and Yang [29] conducted a preliminary study of the relationship between the risk premium coefficient and the skewness in the return distribution on the dimension of time in the same markets. They divided the return series of each market into 4 subsamples of 4 different horizons and found that the risk premium coefficients and the skewness for different time periods in the same market were quite different but were still significantly negatively correlated. The fact that the skewness may vary at different time periods is consistent with many scholars' research conclusions, but there are few studies on the time variation of the risk premium coefficient. The empirical evidences provided by Wen and Yang [29] showed that in the same market the risk premium coefficient may change with the time; that is to say, in reality investors' risk attitude may be different at different time periods under the influence of some factors.

In order to investigate the possible relationship between the risk premium coefficient and the skewness in the return distribution on the time dimension, this paper first studies the time variation of the risk premium coefficient.

Previous studies found that investors' risk aversion varies at different time periods $([33,34]$, etc.). The higher risk aversion means higher return compensation investors demand for unit risk they take, which implies that the risk premium coefficient should vary with time and other factors. Anderson et al. [30] proposed the ANST-GARCH-M model, assuming the risk premium coefficient is related to prior unexpected gains and characterizing the premium coefficient as $\delta_{1}+\delta_{2} F\left(\varepsilon_{t-1}\right)$, where $F\left(\varepsilon_{t-1}\right)=\left\{1+\exp \left[-\gamma\left(\varepsilon_{t-1}\right)\right]\right\}^{-1}$, which essentially allows for the time variation of the risk premium coefficient. Their empirical results also indicated that, in reality, investors' risk tolerance will vary with the time under the influence of prior unexpected gains.

Thaler Richard and Johnson Eric's [35] study gave a tentative explanation to the problem of how prior outcomes affect the risk-taking decision of the current period. Their research suggested that as prior gains can cushion the possible loss of the current period, the investor's risk attitude will be enhanced and thus encourage him to take more risk and even engage in speculation. This phenomenon is called the "house money" effect; the investor, in fact, records prior gains in a specific mental account and thinks that is only "house money." On the contrary, prior losses will increase the investor's current risk aversion, since another loss will make 
the investor feel much more "painful" than the average loss. Based on the above findings, Barberis et al. [36] introduced the utility function of the prospect theory into their capital asset pricing model and discussed that investors' risk aversion will vary due to their prior behaviors in capital asset pricing. According to the prospect theory, the valuation of the gain and the loss is determined according to the selection of the reference point. This paper, based on Barberis et al. [36], assumes that prior gains confirmed by the investor are only the unexpected gains, that is, the unexpected return in the model.

In addition to allowing for the influence of the last-period unexpected return on the investor's risk attitude, this paper further considers the possible influence of other factors. First, as a market participant facing various risks in the market, the investor must have the capacity to tolerate certain degree of risk; that is to say, every investor has the intrinsically invariant potential to speculate; secondly, human's behavior exhibits a certain measure of continuity; current behavior is more or less influenced by prior behavior, and speculative behavior may, to some extent, find its root in prior behavior; finally, conventional theories hold that, in making their investment decisions, investors will unavoidably consider the gain and the loss, and they will take into account the risk factors in addition to the last-period unexpected return. These factors jointly determine the investor's risk attitude. On the basis of the above discussion, this paper proposes the following GARCH-M model allowing for time-varying risk coefficient to further investigate the possible influence of these factors on the investor's risk attitude:

$$
\begin{aligned}
& r_{t}=c+x_{t} \beta+\gamma_{t} f\left(h_{t}\right)+\varepsilon_{t}, \\
& \gamma_{t}=\rho_{0}+\rho_{1} \cdot \gamma_{t-1}+\rho_{2} \cdot \frac{\varepsilon_{t-1}}{f\left(h_{t-1}\right)}, \\
& \varepsilon_{t}=\sqrt{h_{t}} \cdot v_{t}, \\
& h_{t}=\alpha_{0}+\alpha_{1} \varepsilon_{t-1}^{2}+\alpha_{2} h_{t-1} .
\end{aligned}
$$

Different from the original GARCH-M model, our model assumes that the risk premium coefficient is time-varying. In the model, $\rho_{0}$ is the basic risk premium investors demand for a unit of risk, which can be interpreted as the invariant risk premium investors demand for certain kinds of risk inherent in the market for a certain period of time; $\varepsilon_{t-1} / f\left(h_{t-1}\right)$ is the risk adjusted unexpected return of the last period, where $f\left(h_{t}\right)$ is a function of the time-varying variance $h_{t}$ (mostly in the forms of $\left.h_{t}, \sqrt{h_{t}}, \ln \left(h_{t}\right)\right), \rho_{1}$ means that the current risk attitude can be more or less jointly influenced by the unexpected return and the risk of the last period; $\rho_{2}$ expresses that the current risk attitude can be influenced, to a certain extent, by the last-period risk attitude, reflecting the average level of the influence of historical behaviors on the current behavior.

3.2. Autoregressive Conditional Skewness Model Allowing for Time-Varying Risk Premium Coefficient. Harvey and Siddique [18], based on a noncentral $t$ distribution, characterized the time variation of the variance and the skewness simultaneously using a simple autoregressive conditional skewness model, GARCHS $(1,1,1)$ (GARCH with skewness):

$$
\begin{aligned}
& r_{t}=\varphi^{\prime} Z_{t-1}+\varepsilon_{t}, \quad \varepsilon_{t} \mid \Omega_{t-1} \sim N_{t}\left(\nu_{t}, \delta_{t}\right), \\
& h_{t}=\alpha_{0}+\alpha_{1} \varepsilon_{t-1}^{2}+\alpha_{2} h_{t-1}, \\
& s_{t}=\beta_{0}+\beta_{1} \varepsilon_{t-1}^{3}+\beta_{2} s_{t-1},
\end{aligned}
$$

where $r_{t}$ is a variable to be modeled, for example, the index return in the stock market; $\varphi^{\prime} Z_{t-1}$ is the conditional mean, where $Z_{t}$ is an instrumental variable completely based on the information set $\Omega_{t}$; the error term $\varepsilon_{t}$ follows the conditional noncentral $t$ distribution $N_{t}\left(\nu_{t}, \delta_{t}\right) ; h_{t}=\operatorname{Var}_{t-1}\left(r_{t}\right)$ is the conditional variance; $s_{t}=\operatorname{Skew}_{t-1}\left(r_{t}\right)$ is the conditional skewness; and $0<\alpha_{1}<1,0<\alpha_{2}<1 ;-1<\beta_{1}<1,-1<$ $\beta_{2}<1 ; \alpha_{1}+\alpha_{2}<1,-1<\beta_{1}+\beta_{2}<1$.

Estimating models (5) and (6) independently can give us the conditional skewness and the time-varying risk premium coefficient, respectively. Then we can investigate the correlation between them on the dimension of time. But estimating the two models independently is likely to separate the various features of the return series undesirably, which are actually embodied in the return series. It is even more likely that the relationship between the various features of the return series will be distorted, especially when the two models are estimated on the basis of different distribution assumptions. On the other hand, in accounting for the skewness, the distribution assumption for the conventional GARCH-type model fails to describe the time-varying process of the skewness, but the noncentral $t$ distribution can be employed to characterize the time variation of the skewness. Therefore, this paper integrated the above two models into the following GARCH-M model allowing for time-varying risk premium coefficient (for consistency, this paper uses $\sqrt{h_{t}}$ for $f\left(h_{t}\right)$ ):

$$
\begin{aligned}
& r_{t}=c+x_{t} \delta+\gamma_{t} \sqrt{h_{t}}+\varepsilon_{t}, \quad \varepsilon_{t} \mid \Omega_{t-1} \sim N_{t}\left(\nu_{t}, \delta_{t}\right) \\
& \gamma_{t}=\rho_{0}+\rho_{1} \cdot \gamma_{t-1}+\rho_{2} \cdot \frac{\varepsilon_{t-1}}{\sqrt{h_{t-1}}} \\
& h_{t}=\alpha_{0}+\alpha_{1} \varepsilon_{t-1}^{2}+\alpha_{2} h_{t-1}, \\
& s_{t}=\beta_{0}+\beta_{1} \varepsilon_{t-1}^{3}+\beta_{2} s_{t-1} .
\end{aligned}
$$

This model affords a potential tool for further studying the relationship between the risk premium coefficient and the skewness on the dimension of time.

3.3. Model Estimation. The equation of the conditional noncentral $t$ distribution is too complicated, which causes much difficulty in model estimation. León et al. [20] estimated the autoregressive conditional variance, skewness, and kurtosis model using the Gram-Charlier series expansion of the normal density function. $\mathrm{Xu}$ [26], on the basis of León et al's work, proposed that the parameters of $\operatorname{GARCHS}(1,1,1)$ can be estimated using the Gram-Charlier series expansion of the normal density function and truncating at the third 
moment. With the available information set $\Omega_{t-1}$, the approximate expression of the conditional density function of the standardized error $\eta_{t}=\varepsilon_{t} h_{t}^{-1 / 2}$ of the error $\varepsilon_{t}$ can be obtained:

$$
\begin{aligned}
g\left(\eta_{t} \mid I_{t-1}\right) & =\frac{1}{\sqrt{2 \pi}} e^{-\eta_{t}^{2} / 2}\left(1+\frac{s_{t}^{*}}{3 !}\left(\eta_{t}^{3}-3 \eta_{t}\right)\right) \\
& =\phi\left(\eta_{t}\right) \psi^{2}\left(\eta_{t}\right)
\end{aligned}
$$

where $s_{t}^{*}$ denotes the conditional skewness of $\eta_{t} ; \phi\left(\eta_{t}\right)$ is the probability density function of the standard normal distribution, $(1 / \sqrt{2 \pi}) e^{-\eta_{t}^{2} / 2} ; \psi\left(\eta_{t}\right)$ is the polynomial part of the Gram-Charlier series' third-order expansion, $1+\left(s_{t}^{*} / 3 !\right)\left(\eta_{t}^{3}-\right.$ $\left.3 \eta_{t}\right)$. Hence we get the likelihood function of the sample:

$$
\begin{aligned}
\mathrm{SLF}= & -\frac{1}{2}(T-1) \times \ln (2 \pi)-\frac{1}{2} \sum_{t=2}^{T} \ln h_{t}-\frac{1}{2} \sum_{t=2}^{T} \ln \eta_{t}^{2} \\
& +\sum_{t=2}^{T} \ln \left(1+\frac{s_{t}^{*}}{3 !}\left(\eta_{t}^{3}-3 \eta_{t}\right)\right) .
\end{aligned}
$$

However, the likelihood function determined by (8) cannot satisfy the definition of the density function. Based on León et al. [20], this paper modifies it and derives the following probability density function expression:

$$
\begin{aligned}
f\left(\eta_{t} \mid I_{t-1}\right) & =\frac{\phi\left(\eta_{t}\right) \psi^{2}\left(\eta_{t}\right)}{\Gamma_{t}} \\
& =\frac{(1 / \sqrt{2 \pi}) e^{-\eta_{t}^{2} / 2}\left(1+\left(s_{t}^{*} / 3 !\right)\left(\eta_{t}^{3}-3 \eta_{t}\right)\right)^{2}}{\Gamma_{t}}
\end{aligned}
$$

where $\Gamma_{t}=1+s_{t}^{* 2} / 3$ ! is the modified term of the GramCharlier series expansion. Hence we obtain the likelihood function for the sample:

$$
\begin{aligned}
\mathrm{SLF}^{\prime}= & -\frac{1}{2}(T-1) \times \ln (2 \pi)-\frac{1}{2} \sum_{t=2}^{T} \ln h_{t}-\frac{1}{2} \sum_{t=2}^{T} \ln \eta_{t}^{2} \\
& +\sum_{t=2}^{T} \ln \left(\psi^{2}\left(\eta_{t}\right)\right)-\sum_{t=2}^{T} \ln \left(\Gamma_{t}\right) .
\end{aligned}
$$

Solving for the maximum of (11) of the likelihood function of the sample will give us the consistent estimates of the parameters.

As the sample likelihood function is highly nonlinear, the selection of the initial parameters is critical for obtaining the global optimal solution. Harvey and Siddique's [18] strategy of going from the simple model to the complicated model in estimating models has delivered good empirical results and has thus been widely applied. This paper, in line with this strategy, used the following parameter estimation steps:

(1) estimate the equation for the mean and then use the results as the initial values to estimate the GARCH-M model;
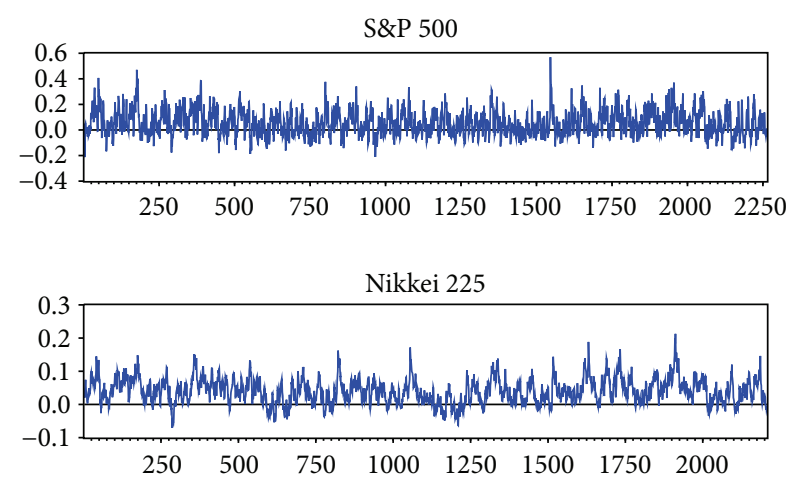

Figure 2: The time-varying processes of the risk premium coefficients gamma.

(2) estimate the GARCH-M model and use the parameter estimation results as the initial values for the estimation of the GARCHS-M model and the GARCH$\mathrm{M}$ model allowing for time-varying risk premium coefficient;

(3) use the parameter estimation results from the above two steps as the initial values to estimate the GARCHS-M model allowing for time-varying risk premium coefficient.

3.4. Empirical Results. The empirical study in this section was divided into two parts: first the estimation results for model (7) were given and analyzed to investigate the reasonability of the specification of the model; then the correlation between the skewness in the return distribution and the degree of speculation in the market on the basis of the empirical results was further investigated.

3.4.1. Results for Model Estimation. We estimated the model (7) using the data of the 14 samples (we run the estimation on Eviews 5.0.) and the estimation results are shown in Table 3.

Using the estimation results, the time-varying processes of the risk premium coefficients were plotted as shown in Figure 2 (for space, only 2 representative indices, S\&P 500 and Nikkei 225, were given here).

Figure 2 gives the time-varying processes of the risk premium coefficients. From the figure we can see that the risk premium coefficient for each market exhibits an obvious time-varying feature and an average significantly greater than zero. This shows that, in general, the more risk there is in the market, the more return compensation investors demand, which is consistent with the conventional finance theory. But under the influence of the risk attitude, the unexpected return, and the risk of the last period, the current risk premium coefficient may be negative in some cases, which means that investors relax their vigilance for risk under the influence of these factors and exhibit obvious irrationality, which may encourage speculative behavior.

From the examination of the estimation results of the time-varying process of the risk premium coefficients, we can see that, apart from the constant term, most of the estimation 
TABLE 3: Model estimation results.

(a)

\begin{tabular}{|c|c|c|c|c|c|c|c|c|}
\hline Parameter & & S\&P 500 & Dow J. & Nasdaq & NYSE & N 225 & FTSE 100 & SSE \\
\hline \multirow{3}{*}{ Time- varying $\gamma$} & $\rho_{0}$ & $\begin{array}{l}0.014061 \\
(0.0668)\end{array}$ & $\begin{array}{l}0.024333 \\
(0.0960)\end{array}$ & $\begin{array}{l}0.073175 \\
(0.0220)\end{array}$ & $\begin{array}{c}0.015498 \\
(0.1171)\end{array}$ & $\begin{array}{c}0.004656 \\
(0.3741)\end{array}$ & $\begin{array}{c}0.022537 \\
(0.0356)\end{array}$ & $\begin{array}{c}0.060807 \\
(0.0767)\end{array}$ \\
\hline & $\rho_{1}$ & $\begin{array}{l}0.671156 \\
(0.0000)\end{array}$ & $\begin{array}{l}0.548122 \\
(0.0059)\end{array}$ & $\begin{array}{c}-0.672522 \\
(0.0011)\end{array}$ & $\begin{array}{l}0.699180 \\
(0.0000)\end{array}$ & $\begin{array}{c}0.864550 \\
(0.0000)\end{array}$ & $\begin{array}{l}0.552242 \\
(0.0000)\end{array}$ & $\begin{array}{c}-0.802902 \\
(0.0013)\end{array}$ \\
\hline & $\rho_{2}$ & $\begin{array}{c}-0.070729 \\
(0.0002)\end{array}$ & $\begin{array}{c}-0.056227 \\
(0.0098) \\
\end{array}$ & $\begin{array}{c}0.034182 \\
(0.0169) \\
\end{array}$ & $\begin{array}{c}-0.045118 \\
(0.0142) \\
\end{array}$ & $\begin{array}{c}-0.017348 \\
(0.1723)\end{array}$ & $\begin{array}{c}-0.082743 \\
(0.0000)\end{array}$ & $\begin{array}{c}0.018254 \\
(0.2415)\end{array}$ \\
\hline \multirow{3}{*}{ Variance equation } & $\alpha_{0}$ & $\begin{array}{l}0.011472 \\
(0.0000)\end{array}$ & $\begin{array}{l}0.011674 \\
(0.0000)\end{array}$ & $\begin{array}{l}0.010696 \\
(0.0000)\end{array}$ & $\begin{array}{l}0.014906 \\
(0.0000)\end{array}$ & $\begin{array}{c}0.020784 \\
(0.0038)\end{array}$ & $\begin{array}{l}0.010016 \\
(0.0002)\end{array}$ & $\begin{array}{l}0.041504 \\
(0.0000)\end{array}$ \\
\hline & $\alpha_{1}$ & $\begin{array}{c}0.075448 \\
(0.0000)\end{array}$ & $\begin{array}{l}0.081726 \\
(0.0000)\end{array}$ & $\begin{array}{c}0.046647 \\
(0.0000)\end{array}$ & $\begin{array}{c}0.078346 \\
(0.0000)\end{array}$ & $\begin{array}{c}0.092420 \\
(0.0000)\end{array}$ & $\begin{array}{l}0.096733 \\
(0.0000)\end{array}$ & $\begin{array}{c}0.099855 \\
(0.0000)\end{array}$ \\
\hline & $\alpha_{2}$ & $\begin{array}{l}0.913434 \\
(0.0000)\end{array}$ & $\begin{array}{c}0.908752 \\
(0.0000)\end{array}$ & $\begin{array}{c}0.945602 \\
(0.0000)\end{array}$ & $\begin{array}{c}0.906232 \\
(0.0000)\end{array}$ & $\begin{array}{c}0.900605 \\
(0.0000)\end{array}$ & $\begin{array}{c}0.894667 \\
(0.0000)\end{array}$ & $\begin{array}{c}0.893033 \\
(0.0000)\end{array}$ \\
\hline \multirow{3}{*}{ Skewness equation } & $\beta_{0}$ & $\begin{array}{c}-0.000538 \\
(0.0046)\end{array}$ & $\begin{array}{c}-0.001420 \\
(0.0311)\end{array}$ & $\begin{array}{c}-0.045664 \\
(0.0017)\end{array}$ & $\begin{array}{c}-0.000449 \\
(0.0010)\end{array}$ & $\begin{array}{c}-0.046385 \\
(0.0385)\end{array}$ & $\begin{array}{c}-0.008635 \\
(0.1683)\end{array}$ & $\begin{array}{c}0.020711 \\
(0.0143)\end{array}$ \\
\hline & $\beta_{1}$ & $\begin{array}{c}0.001963 \\
(0.0235)\end{array}$ & $\begin{array}{c}0.004560 \\
(0.0516)\end{array}$ & $\begin{array}{c}0.032296 \\
(0.0000)\end{array}$ & $\begin{array}{l}0.003019 \\
(0.0067)\end{array}$ & $\begin{array}{c}0.028283 \\
(0.0016)\end{array}$ & $\begin{array}{l}0.011915 \\
(0.0359)\end{array}$ & $\begin{array}{c}0.006473 \\
(0.0442)\end{array}$ \\
\hline & $\beta_{2}$ & $\begin{array}{l}0.987139 \\
(0.0000) \\
\end{array}$ & $\begin{array}{l}0.959255 \\
(0.0000) \\
\end{array}$ & $\begin{array}{l}0.533682 \\
(0.0000)\end{array}$ & $\begin{array}{l}0.983791 \\
(0.0000) \\
\end{array}$ & $\begin{array}{l}0.595621 \\
(0.0000) \\
\end{array}$ & $\begin{array}{c}0.843206 \\
(0.0000)\end{array}$ & $\begin{array}{l}0.626719 \\
(0.0003) \\
\end{array}$ \\
\hline Log likelihood & & -1243.670 & -1154.630 & -1926.634 & -1172.428 & -1845.429 & -1203.899 & -2086.479 \\
\hline
\end{tabular}

(b)

\begin{tabular}{ccccccccc}
\hline Parameter & & DAX & CAC 40 & GSPTSE & MIBTEL & IGBM & BVSP & Hangseng \\
\hline & \multirow{2}{c}{$\rho_{0}$} & 0.013762 & 0.012604 & 0.012297 & 0.035950 & 0.021461 & 0.014801 & 0.007973 \\
& & $(0.1821)$ & $(0.0681)$ & $(0.2773)$ & $(0.2338)$ & $(0.5686)$ & $(0.1713)$ & $(0.7020)$ \\
Time- varying $\gamma$ & $\rho_{1}$ & 0.771009 & 0.744133 & 0.754400 & 0.082012 & 0.761071 & 0.728769 & 0.843089 \\
& & $(0.0000)$ & $(0.0000)$ & $(0.0002)$ & $(0.8789)$ & $(0.0623)$ & $(0.0000)$ & $(0.0367)$ \\
& $\rho_{2}$ & -0.031714 & -0.053187 & -0.024171 & -0.036640 & -0.013422 & -0.032091 & -0.007450 \\
& & $(0.0562)$ & $(0.0023)$ & $(0.1279)$ & $(0.0961)$ & $(0.4694)$ & $(0.0483)$ & $(0.6257)$ \\
\hline & \multirow{2}{*}{$\alpha_{0}$} & 0.016197 & 0.014882 & 0.008462 & 0.009467 & 0.017090 & 0.099432 & 0.015302 \\
& & $(0.0002)$ & $(0.0001)$ & $(0.0000)$ & $(0.0000)$ & $(0.0000)$ & $(0.0000)$ & $(0.0003)$ \\
Variance equation & \multirow{2}{*}{$\alpha_{1}$} & 0.089870 & 0.080974 & 0.072330 & 0.097325 & 0.089791 & 0.072369 & 0.067647 \\
& & $(0.0000)$ & $(0.0000)$ & $(0.0000)$ & $(0.0000)$ & $(0.0000)$ & $(0.0000)$ & $(0.0000)$ \\
& \multirow{2}{*}{$\alpha_{2}$} & 0.902930 & 0.909675 & 0.918544 & 0.895624 & 0.897541 & 0.894363 & 0.925600 \\
& & $(0.0000)$ & $(0.0000)$ & $(0.0000)$ & $(0.0000)$ & $(0.0000)$ & $(0.0000)$ & $(0.0000)$ \\
\hline & \multirow{2}{*}{$\beta_{0}$} & -0.044249 & -0.012939 & -0.001743 & -0.008658 & -0.008764 & -0.080287 & -0.003197 \\
& & $(0.3287)$ & $(0.0441)$ & $(0.0042)$ & $(0.1932)$ & $(0.2645)$ & $(0.0413)$ & $(0.5593)$ \\
Skewness equation & \multirow{2}{*}{$\beta_{1}$} & 0.013195 & 0.018179 & 0.006174 & 0.007836 & 0.010878 & 0.008073 & 0.001812 \\
& & $(0.2559)$ & $(0.0018)$ & $(0.0001)$ & $(0.0224)$ & $(0.1647)$ & $(0.0333)$ & $(0.4276)$ \\
& \multirow{2}{*}{$\beta_{2}$} & 0.636849 & 0.852436 & 0.964743 & 0.880261 & 0.750425 & 0.909746 & 0.945101 \\
& & $(0.0780)$ & $(0.0000)$ & $(0.0000)$ & $(0.0000)$ & $(0.0005)$ & $(0.0000)$ & $(0.0000)$ \\
\hline Log likelihood & & -1815.479 & -1665.186 & -1046.193 & -1071.693 & -1130.580 & -2450.400 & -1753.907 \\
\hline
\end{tabular}

results for $\rho_{1}$ and $\rho_{2}$ are significant at $10 \%$; although $\rho_{2}$ for Nikkei 225, SSE, and GSPTSE are not significant at 10\%, the corresponding $P$ values are relatively small $(0.1723,0.2415$, and 0.1279 , resp.). Only the $P$ values for $\rho_{1}$ for MIBTEL and $\rho_{2}$ for IGBM and Hangseng are relatively big $(0.8789,0.4694$, and 0.6257 , resp.), and the estimation results are obviously not significant. But for all the estimation results there are no cases where the estimation results for the two coefficients of $\rho_{1}$ and $\rho_{2}$, which determine time variation of the risk premium coefficient, are not significant at the same time. This fact indicates that time variation does exist for the risk premium coefficient, and it is reasonable to assume that the risk premium coefficient for the model is time-varying.

Among the 14 estimation results for the samples, $\rho_{0}$ are all positive and most of them are significant, which imply the risk premium investors demand for unit risk is positive, and the result is consistent with the traditional theory. This can be regarded as the risk premium investors demand for the risk inherent in the market for a certain period of time. Except for the estimation results for NASDAQ and SSE, the other results for $\rho_{1}$ are positive and approximate to 1 (the result for MIBTEL is 0.082012 , rather small), which means 
that the current risk attitude is influenced by the persistence of the last-period risk attitude and diminishes a little. The estimation results for $\rho_{2}$ for the samples are all smaller than zero. This indicates that the positive unexpected return after risk adjustment will reduce the risk premium investors demand for unit risk. It can also be viewed as that when the basic risk remains unchanged in the market, the higher the unexpected return is in the last period, the smaller the risk premium coefficient is; this indicates that investors' current risk tolerance is higher and the degree of speculation is also higher; if the unexpected return in the last period is positive, the more riskier it was in the last period, the higher the premium coefficient is, which shows that investors' current risk tolerance is lower than that of the last period, and also lower is the degree of speculation; if the unexpected return is negative in the last period, the more riskier it was in the last period, the smaller the risk premium coefficient is, which shows that investors' current risk tolerance is higher than that of the last period, and also higher is the degree of speculation.

However, the signs of $\rho_{1}$ and $\rho_{2}$ of the estimation results for the samples of NASDAQ and SSE are just the opposite of those for other samples. The fact that $\rho_{1}$ is negative with its absolute value less than 1 indicates that investors' current risk attitude will show a reversal in the nest period in the above 2 markets; that is to say, the higher the risk tolerance for the current period is, the higher the possibility there is for it to become lower for the next period, and the behavior intensity of the risk tolerance will weaken; the sign of $\rho_{2}$ is negative, which implies the risk-adjusted positive unexpected return will drive up investors' unit risk premium. With the risk remaining fundamentally unchanged, the influence of the unexpected return on the degree of speculation is just the opposite to those on other markets. The higher the unexpected return for the last period is, the more likely the risk tolerance is to become higher; that is to say, the degree of speculation is more likely to decrease. This will cause investors to become more cautious in trading, which is the typical psychology to keep the profit.

It is well known that NASDAQ and SSE are widely recognized as two markets with relatively high speculation; the completely different risk tolerance behavior of the two markets from the other markets may be possibly determined by the degrees of speculation on the two markets. Accordingly, we set to investigate the influence of the market risk on the degrees of speculation in the two markets. When the unexpected return is positive and remains basically unchanged, the market is relatively bullish. The fact that the estimation results of $\rho_{2}$ for the two markets are positive indicates that the higher the risk for the last period is, the smaller the risk premium coefficient for the current period is; that is, the higher the risk tolerance is, the higher the speculation degree is; when the unexpected return is negative and remains basically unchanged, the market is relatively bearish. In that case, the positive $\rho_{2}$ implies that the higher the risk is for the last period, the smaller the risk premium coefficient is for the current period; that is to say, the smaller the risk tolerance is, the lower the degree of speculation is. This implies that when it is bullish, investors, more often than not, seek risks in NASDAQ and SSE, and the higher the risk is, the more likely it is for investors to engage in speculation, while investors tend to evade risk, when the market is bearish, and increased risk will reduce speculation in the market. In a mature market, investors reaction to risk is completely different from investors in the above two markets: investors prefer relatively low risk for stable return in a bullish market, and increased risk will lead to less speculation, while they prefer relatively higher risk, which will prompt speculation in the market.

The above discussion shows that there is striking difference in investors' reaction to the return and the risk in a speculative market and a mature market, which may serve as an indicator for whether the market is mature or not.

Besides, it can be seen from the examination of the estimation results of the coefficient of the skewness process that the conditional skewness process (not including the constant term) of most of the indices is significant at $10 \%$ (DAX, IGBM, and Hangseng are excluded, but part of the coefficients for DAX and IGBM and the corresponding $P$ value are relatively small, being 0.2559 and 0.1647 , resp.). This shows that the time variation of the skewness is well characterized. As the conditional skewness process has been well studied, this paper will not discuss much about the estimation results.

3.4.2. The Relationship between the Risk Premium Coefficient and the Skewness. From the above discussion we can see that the GARCHS-M model with the time-varying risk premium coefficient can well characterize the conditional skewness process and the time variation process of the risk premium coefficient of the 14 stock indices simultaneously. On the basis of the estimation results, this paper will further examine the relationship between the risk premium coefficient and the skewness on the dimension of time.

First, we will plot the conditional skewness and the risk premium coefficient of the 14 indices, as shown in Figure 3 (for S\&P 500 and Nikkei 225), where the line is the regression line. The Pearson correlation can only measure the linear correlation between the variables [37], but the scatter plots will give us the impression that the relationship between the risk premium coefficient and the skewness may be complicated. Consequently, this paper will select Kendall's tau and Spearman's rho to measure whether the 2 variables' variation tendencies are in the same direction. The values for the 2 correlations of the 2 variables are given in Table 4 .

It can be seen from Tables 3 and 4, except NASDAQ and SSE, that the conditional skewness and the risk premium coefficient are significantly negatively correlated. The significantly negative correlation further corroborated Wen and Yang's [29] viewpoints: the high degree of speculation in the market will cause the positive skew in the return distribution. It can be shown with further investigation of the causes for the negative correlation using models and their estimation results: in general, the conditional skewness is positively correlated with the cube of the unexpected return, while the risk premium coefficient is negatively correlated with the unexpected return. The different reactions to the unexpected return are possibly the main causes for 

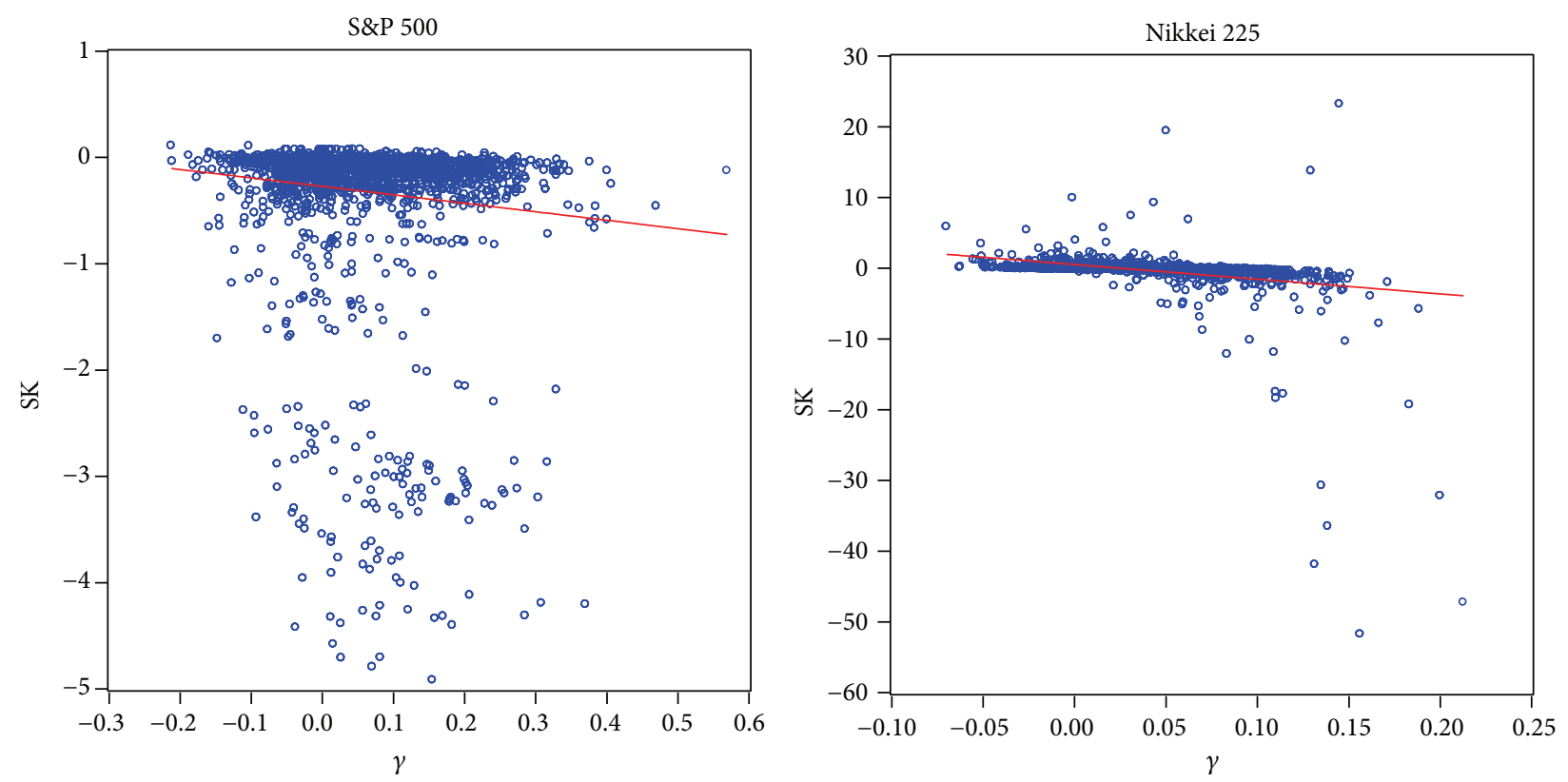

FIGURE 3: The scatter plots of the relationship between the risk premium coefficient gamma and the conditional skewness.

TABLE 4: The correlation between the risk premium coefficient gamma and the conditional skewness.

(a)

\begin{tabular}{lcccccrr}
\hline & S\&P 500 & Dow J. & NASDAQ & NYSE & N 225 & FTSE 100 & SSE \\
\hline Pearson correlation & -0.106 & -0.223 & 0.175 & -0.118 & -0.308 & -0.246 & 0.158 \\
Kendall's tau & -0.144 & -0.200 & 0.193 & -0.175 & -0.558 & -0.415 & 0.130 \\
Spearman's rho & -0.211 & -0.295 & 0.272 & -0.255 & -0.756 & -0.591 & 0.183 \\
\hline
\end{tabular}

(b)

\begin{tabular}{lccccccc}
\hline & DAX & CAC 40 & GSPTSE & MIBTEL & IGBM & BVSP & Hangseng \\
\hline Pearson correlation & -0.438 & -0.402 & -0.156 & -0.232 & -0.358 & -0.474 & -0.371 \\
Kendall's tau & -0.619 & -0.514 & -0.250 & -0.218 & -0.609 & -0.460 & -0.449 \\
Spearman's rho & -0.818 & -0.714 & -0.368 & -0.321 & -0.808 & -0.644 & -0.632 \\
\hline
\end{tabular}

Note: all the values are significantly different from zero at $1 \%$ level.

the negative correlation. Behavioral finance research findings show that the nonnormality of the return distribution is caused by investors' behavioral biases, and the unexpected return series (i.e., the error series) can be viewed as the proxy of the information flow, so we might as well think that the negative correlation is essentially caused by investors' different reactions to information.

On the contrary, the conditional skewness and the risk premium coefficient of the NASDAQ and the SSE are significantly positively correlated, which is also consistent with the findings of Wen and Yang [29]. It can be seen from the scatter plots that none of the correlations between the risk premium coefficient and the conditional skewness for all the markets is linear. Simply judging from the degree of consistency of the tendencies in the changes of the two variables, even in the case of low linear correlation, the directions in the changes are usually of high degree of consistency. This shows that the influence of speculation on the skewness in the return distribution is not linear and may have a very complex mechanism. Apart from speculation in the market, the skewness in the return distribution may be attributed to other factors, which partly explains the complicated relationship between the speculation and the skewness in the return distribution.

\section{Conclusions}

This paper characterizes the time variation of the risk premium coefficient, that is, how investors' risk attitude varies with the time. By proposing a modified GARCH-M model and using the daily return series of the representative 14 stock indices as samples, this paper empirically investigates the correlation of the skewness in the return distribution and the risk premium coefficient, and the empirical results show the following. 
Firstly, the risk premium coefficient is obviously timevarying, and the current risk premium investors demand for unit risk is influenced not only by the last-period unexpected return and the risk but also by the persistence of the risk attitude for the last period. Secondly, there is significant difference in investors' reactions to the return and the risk in a speculative market and a mature market: in a mature market investors prefer low risk for a stable return when the market is bullish, while they seek relatively high risk when it is bearish and may trigger more speculation in the market. Lastly, the skewness in the return distribution and the risk premium coefficient is significantly negatively correlated even in a mature market when examined on the dimension of time.

The above results of this paper further validate the correlation between the skewness in the return distribution and the degree of speculation in the market. Meanwhile, the results also show that the influence of speculation on the skewness in the return distribution is rather complicated. It is necessary and meaningful to further investigate the deep-seated relationship between the skewness in the return distribution and speculation, and the possible influence of other factors on the skewness in the return distribution, such as the cultural background of the market participants, and the microstructure of the market.

\section{Conflict of Interests}

The authors declare that they have no conflict of interests regarding the publication of this paper.

\section{Acknowledgment}

This paper is supported by the Natural Science Foundation of China (71171024 and 71131007).

\section{References}

[1] A. Peiró, "Skewness in individual stocks at different investment horizons," Quantitative Finance, vol. 2, pp. 139-185, 2002.

[2] E. Jondeau and M. Rockinger, "Testing for differences in the tails of stock-market returns," Journal of Empirical Finance, vol. 10, no. 5, pp. 559-581, 2003.

[3] Y.-T. Chen and C.-C. Lin, "On the robustness of symmetry tests for stock returns," Studies in Nonlinear Dynamics and Econometrics, vol. 12, no. 2, article 2, 2008.

[4] P. Samuelson, "The fundamental approximation of theorem in portfolio analysis in terms of means, variances and higher moments," Review of Economic Studies, vol. 37, pp. 537-542, 1970.

[5] T.-Y. Lai, "Portfolio selection with skewness: a multipleobjective approach," Review of Quantitative Finance and Accounting, vol. 1, no. 3, pp. 293-305, 1991.

[6] A. J. Prakash, C.-H. Chang, and T. E. Pactwa, "Selecting a portfolio with skewness: recent evidence from US, European, and Latin American equity markets," Journal of Banking and Finance, vol. 27, no. 7, pp. 1375-1390, 2003.
[7] M. A. Canela and E. P. Collazo, "Portfolio selection with skewness in emerging market industries," Emerging Markets Review, vol. 8, no. 3, pp. 230-250, 2007.

[8] V. Zakamouline and S. Koekebakker, "Portfolio performance evaluation with generalized Sharpe ratios: beyond the mean and variance," Journal of Banking and Finance, vol. 33, no. 7, pp. 1242-1254, 2009.

[9] R. C. Merton, "On estimating the expected return on the market," Journal of Financial Economics, vol. 8, pp. 323-361, 1980.

[10] D. Duffie, J. Pan, and K. Singleton, "Transform analysis and asset pricing for affine jump-diffusions," Econometrica, vol. 68, no. 6, pp. 1343-1376, 2000.

[11] D. R. Smith, "Conditional coskewness and asset pricing," Journal of Empirical Finance, vol. 14, no. 1, pp. 91-119, 2007.

[12] X. Li, Z. Qin, and S. Kar, "Mean-variance-skewness model for portfolio selection with fuzzy returns," European Journal of Operational Research, vol. 202, no. 1, pp. 239-247, 2010.

[13] T. Bollerslev, "Generalized autoregressive conditional heteroskedasticity," Journal of Econometrics, vol. 31, no. 3, pp. 307327,1986

[14] J. C. Singleton and J. R. Wingender, "Skewness persistence in common stock returns," Journal of Financial and Quantitative Analysis, vol. 21, pp. 335-341, 1986.

[15] H. S. Lau and J. R. Wingender, "The analytics of the intervaling effect on skewness and kurtosis of stock returns," The Financial Review, vol. 24, pp. 215-233, 1989.

[16] K. Muralidhar, "The bootstrap approach for testing skewness persistence," Management Science, vol. 39, pp. 487-491, 1993.

[17] C. J. Adcock and K. Shutes, "An analysis of skewness and skewness persistence in three emerging markets," Emerging Markets Review, vol. 6, no. 4, pp. 396-418, 2005.

[18] C. R. Harvey and A. Siddique, "Autoregressive conditional skewness," Journal of Financial and Quantitative Analysis, vol. 34, pp. 465-552, 1999.

[19] M. M. Pelagatti, "Modelling good and bad volatility," Studies in Nonlinear Dynamics and Econometrics, vol. 13, no. 1, article 2, 2009.

[20] A. León, G. Rubio, and G. Serna, "Autoregresive conditional volatility, skewness and kurtosis," Quarterly Review of Economics and Finance, vol. 45, no. 4-5, pp. 599-618, 2005.

[21] F. Chan, "Modelling time-varying higher moments with maximum entropy density," Mathematics and Computers in Simulation, vol. 79, no. 9, pp. 2767-2778, 2009.

[22] G. Bakshi, N. Kapadia, and D. Madan, "Stock return characteristics, skewness law, and the differential pricing of individual equity option," Review of Financial Studies, vol. 16, no. 1, pp. 101143, 2003.

[23] A. Ekholm and D. Pasternack, "The negative news thresholdan explanation for negative skewness in stock returns," European Journal of Finance, vol. 11, no. 6, pp. 511-529, 2005.

[24] F. Wen, D. Huang, Q. Lan, and X. Yang, "Return distribution under behavioral biases: a simulation study," in Proceeding of the joint conference on information sciences, 2006.

[25] K.-H. Bae, C. Lim, and K. C. John Wei, "Corporate governance and conditional skewness in the world's stock markets," Journal of Business, vol. 79, no. 6, pp. 2999-3028, 2006.

[26] J. Xu, "Price convexity and skewness," Journal of Finance, vol. 62 , no. 5, pp. 2521-2552, 2007. 
[27] E. Hutson, C. Kearney, and M. Lynch, "Volume and skewness in international equity markets," Journal of Banking and Finance, vol. 32, no. 7, pp. 1255-1268, 2008.

[28] R. Albuquerque, "Skewness in Stock Returns, Periodic Cash Payouts, and Investor Heterogeneity," CEPR Discussion Papers, 2009.

[29] F. Wen and X. Yang, "Skewness of return distribution and coefficient of risk premium," Journal of Systems Science and Complexity, vol. 22, no. 3, pp. 360-371, 2009.

[30] H. M. Anderson, K. Nam, and F. Vahid, "An asymmetric nonlinear smooth-transition GARCH model," in Nonlinear Time Series Analysis of Economic and Financial Data, P. Rothman, Ed., Kluwer Academic Publishers, Boston, Mass, USA, 1999.

[31] T.-H. Kim and H. White, "On more robust estimation of skewness and kurtosis," Finance Research Letters, vol. 1, no. 1, pp. 56-73, 2004.

[32] R. A. Groeneveld and G. Meeden, "Measuring skewness and kurtosis," The Statistician, vol. 33, pp. 391-399, 1984.

[33] G. Li, “Time-varying risk aversion and asset prices," Journal of Banking and Finance, vol. 31, no. 1, pp. 243-257, 2007.

[34] J. Cotter and J. Hanly, "Time-varying risk aversion: an application to energy hedging," Energy Economics, vol. 32, no. 2, pp. 432-441, 2010.

[35] H. Thaler Richard and J. Johnson Eric, "Gambling with the house money and trying to break even: the effects of prior outcomes on risky choice," Management Science, vol. 36, no. 6, pp. 643-660, 1990.

[36] N. Barberis, M. Huang, and T. Santos, "Prospect theory and asset prices," Quarterly Journal of Economics, vol. 116, no. 1, pp. 1-53, 2001.

[37] F. Wen and Z. Liu, "A copula-based correlation measure and its application in chinese stock market," International Journal of Information Technology and Decision Making, vol. 8, no. 4, pp. 787-801, 2009. 


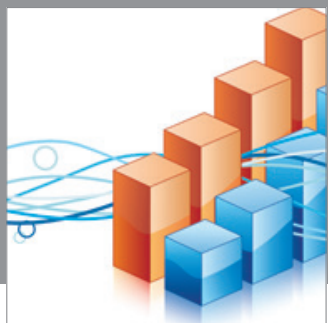

Advances in

Operations Research

mansans

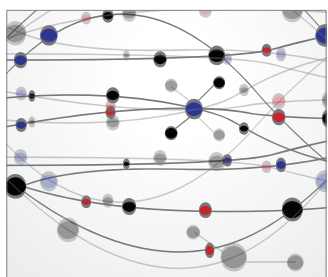

The Scientific World Journal
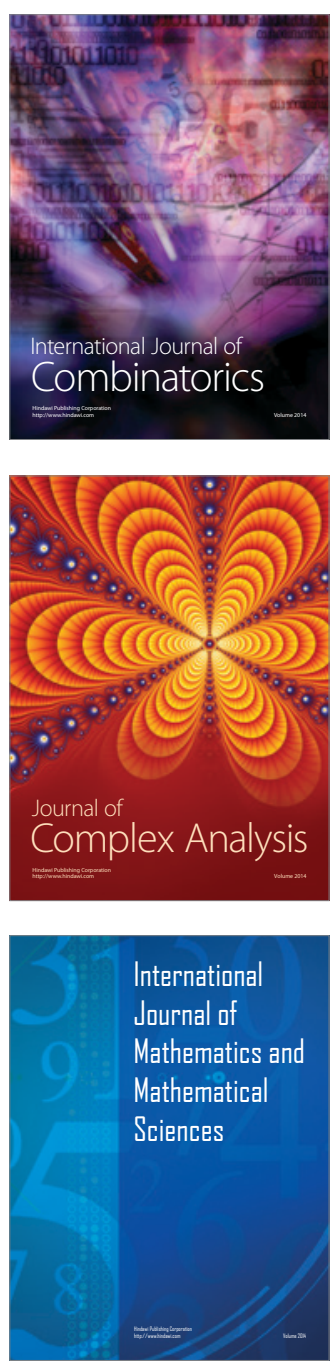
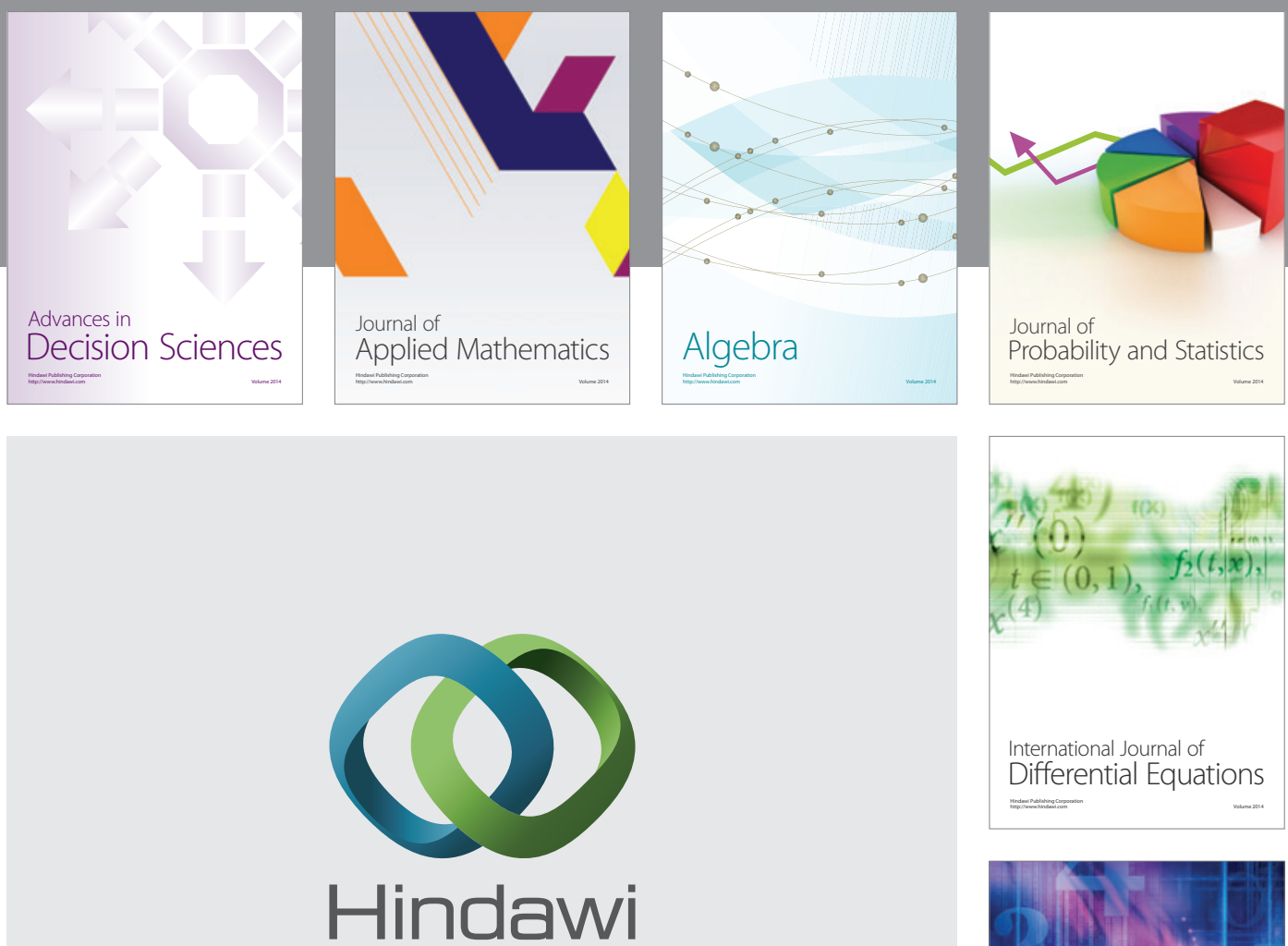

Submit your manuscripts at http://www.hindawi.com
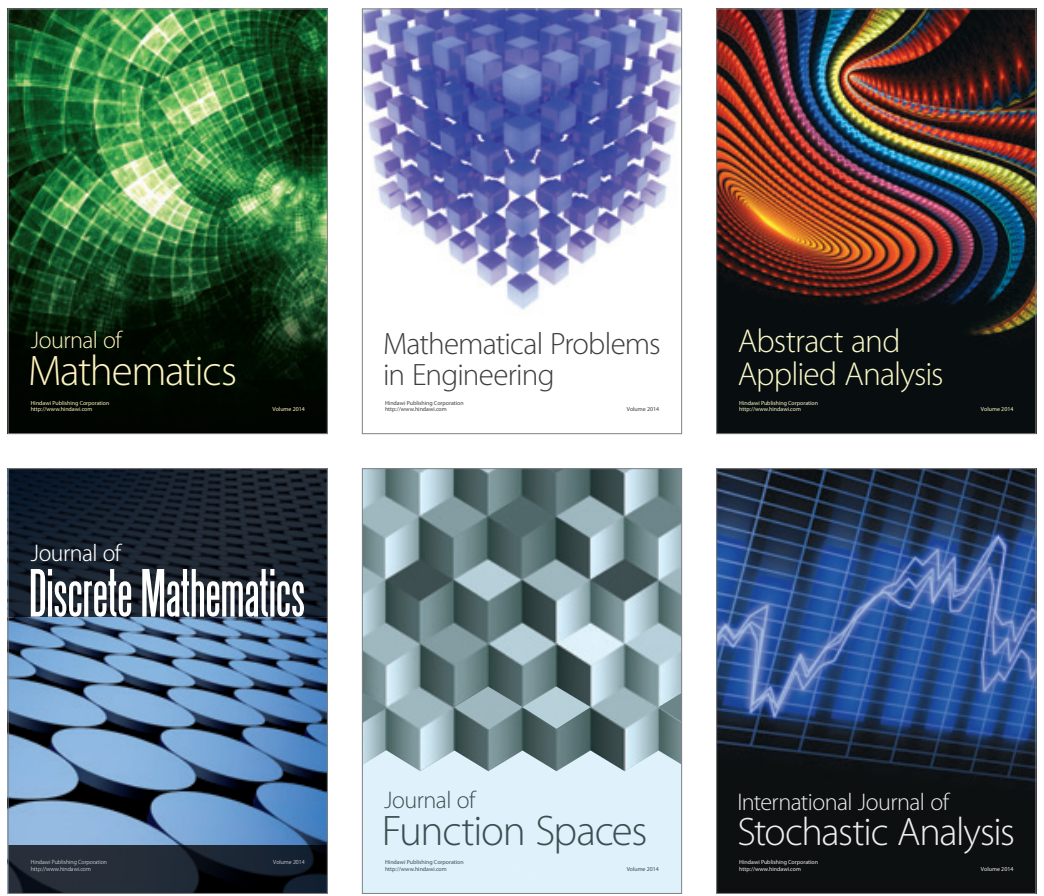

Journal of

Function Spaces

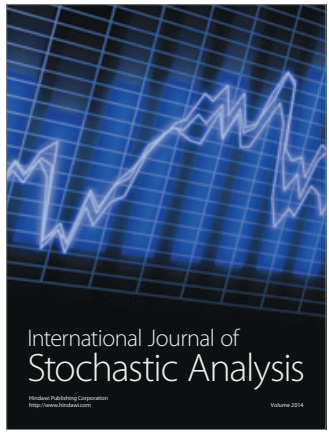

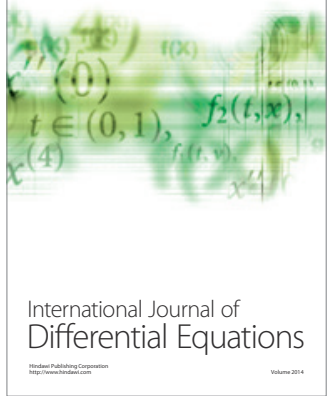
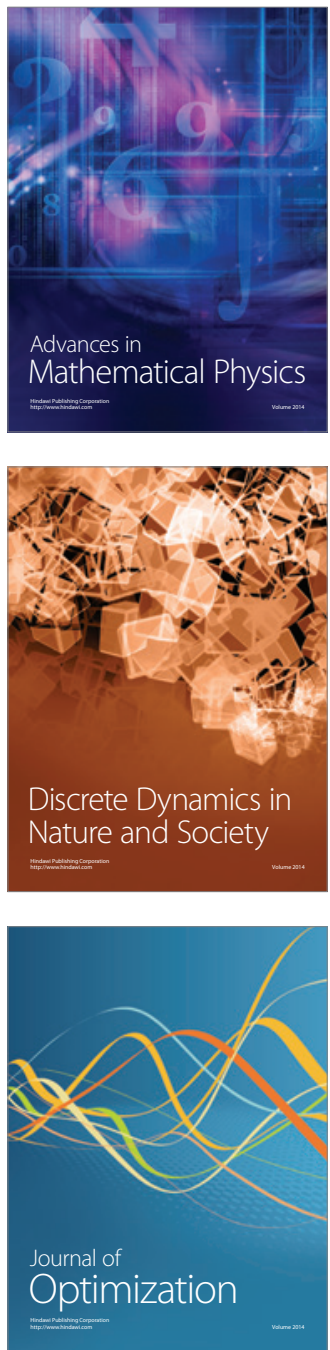